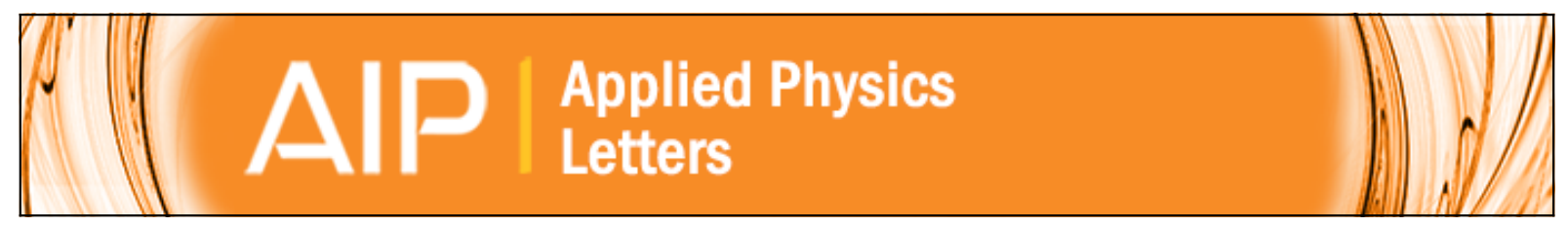

\title{
Composite cathode based on yttria stabilized bismuth oxide for low-temperature solid
} oxide fuel cells

Changrong Xia, Yuelan Zhang, and Meilin Liu

Citation: Applied Physics Letters 82, 901 (2003); doi: 10.1063/1.1542933

View online: http://dx.doi.org/10.1063/1.1542933

View Table of Contents: http://scitation.aip.org/content/aip/journal/apl/82/6?ver=pdfcov

Published by the AIP Publishing

\section{Articles you may be interested in}

Microstructural coarsening effects on redox instability and mechanical damage in solid oxide fuel cell anodes J. Appl. Phys. 114, 183519 (2013); 10.1063/1.4830015

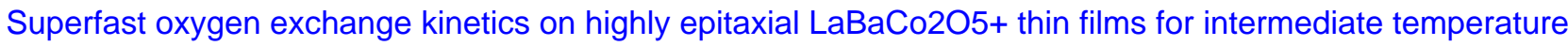
solid oxide fuel cells

APL Mat. 1, 031101 (2013); 10.1063/1.4820363

Computational fluid dynamics model development on transport phenomena coupling with reactions in intermediate temperature solid oxide fuel cells

J. Renewable Sustainable Energy 5, 021420 (2013); 10.1063/1.4798789

Redox instability, mechanical deformation, and heterogeneous damage accumulation in solid oxide fuel cell anodes

J. Appl. Phys. 112, 036102 (2012); 10.1063/1.4745038

Higher ionic conductive ceria-based electrolytes for solid oxide fuel cells Appl. Phys. Lett. 91, 144106 (2007); 10.1063/1.2794725

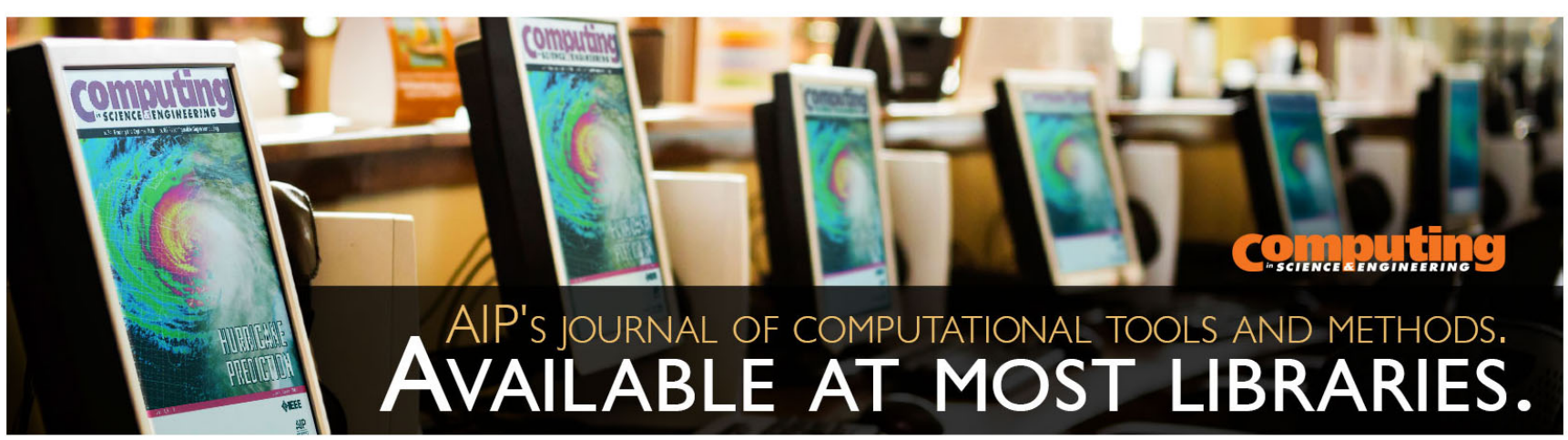




\title{
Composite cathode based on yttria stabilized bismuth oxide for low-temperature solid oxide fuel cells
}

\author{
Changrong Xia, Yuelan Zhang, and Meilin Liu ${ }^{\mathrm{a})}$ \\ School of Materials Science and Engineering, Center for Innovative Fuel Cell and Battery Technologies, \\ Georgia Institute of Technology, Atlanta, Georgia 30332-0245
}

(Received 26 August 2002; accepted 9 December 2002)

\begin{abstract}
Composites consisting of silver and yttria stabilized bismuth oxide (YSB) have been investigated as cathodes for low-temperature honeycomb solid oxide fuel cells with stabilized zirconia as electrolytes. At $600{ }^{\circ} \mathrm{C}$, the interfacial polarization resistances of a porous YSB-Ag cathode is about $0.3 \Omega \mathrm{cm}^{2}$, more than one order of magnitude smaller than those of other reported cathodes on stabilized zirconia. For example, the interfacial resistances of a traditional YSZ-lanthanum maganites composite cathode is about $11.4 \Omega \mathrm{cm}^{2}$ at $600^{\circ} \mathrm{C}$. Impedance analysis indicated that the performance of an YSB-Ag composite cathode fired at $850^{\circ} \mathrm{C}$ for $2 \mathrm{~h}$ is severely limited by gas transport due to insufficient porosity. The high performance of the YSB-Ag cathodes is very encouraging for developing honeycomb fuel cells to be operated at temperatures below $600{ }^{\circ} \mathrm{C}$.

(C) 2003 American Institute of Physics. [DOI: 10.1063/1.1542933]
\end{abstract}

Stabilized zirconias are the most commonly used electrolytes in solid oxide fuel cells (SOFCs) because of their excellent mechanical strength and outstanding thermal/ chemical stabilities in both oxidizing and reducing atmospheres. Due to their limited ionic conductivities, however, SOFCs based on a zirconia electrolyte must be operated at high temperatures $\left(800-1000{ }^{\circ} \mathrm{C}\right)$ to overcome Ohmic losses. Recent advancements in deposition of thin film electrolytes makes it possible to reduce the operating temperature to $600{ }^{\circ} \mathrm{C}$ and below. ${ }^{1-3}$ For example, with hydrogen as fuel and air as oxidant, calculated power densities over $400 \mathrm{mWcm}^{-2}$ at $600^{\circ} \mathrm{C}$ are expected with a $30-\mu \mathrm{m}$-thick scandia stabilized zirconia electrolyte, assuming that the anodic and cathodic interfacial polarization resistances are 0.2 and $0.3 \Omega \mathrm{cm}^{2}$, respectively. Further, the power densities of SOFCs based on thin films of stabilized zirconia can be enhanced by using a honeycomb design. ${ }^{4,5}$ While the anodic interfacial resistance is relatively small, the cathodic interfacial resistance is very large; it actually determines the performance of SOFCs operated at low temperatures (below $\left.600^{\circ} \mathrm{C}\right) .^{6}$

One of the advantages of low-temperature SOFC is the potential for dramatic cost reduction. If SOFCs can be operated below $600^{\circ} \mathrm{C}$, for example, many components (such as the interconnect and heat exchangers) can be fabricated from much less expensive materials. Additional benefits of lower operating temperature include greater system reliability, longer operational life, and increased potential for mobile applications and for cost-effective fabrication. ${ }^{7}$

The development of cathode materials for SOFCs based on yttria-stabilized zirconia (YSZ) has mainly focused on strontium-doped lanthanum manganites (LSM) because of the thermal and chemical compatibilities with YSZ. However, single phase LSM does not have acceptable performance due to its low oxygen-ion conductivity. The addition

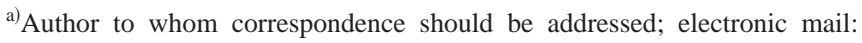
meilin.liu@mse.gatech.edu
}

of a second phase of higher ionic conductivity to LSM may extend the active area over which the oxygen reduction reaction can take place. Composite cathodes consisting of LSM and YSZ or gadolinia doped ceria (GDC) are studied and better performances were achieved at high temperatures. For example, interfacial resistance as low as $0.49 \Omega \mathrm{cm}^{2}$ at $750{ }^{\circ} \mathrm{C}$ was reported for the interface between a LSM-GDC cathode and a YSZ electrolyte. ${ }^{8}$ Recently, interfacial polarization resistance as low as $0.7 \Omega \mathrm{cm}^{2}$ was observed for a functionally graded cathode based on LSM and $\mathrm{YSZ}^{9}$ at $900^{\circ} \mathrm{C}$. However, the interfacial resistances increased dramatically as the operating temperature is reduced to below $600^{\circ} \mathrm{C}$. It is very likely that only limited improvements of LSM cathodes are achievable because the coefficients for oxygen surface exchange and oxygen diffusion in LSM are relatively low. ${ }^{6}$ To efficiently operate a zirconia-based SOFC at $600{ }^{\circ} \mathrm{C}$ or below, it is necessary to develop cathode materials with high catalytic activity for oxygen reduction and with high oxygen ion conductivity for oxygen transport through the composite cathode.

Among the oxygen ion conductors developed, bismuth oxides have showed favorable catalytic effects on the oxygen disassociation reaction, ${ }^{10}$ which is often the rate limiting step in many electrochemical process involving oxygen reduction, such as the one in an SOFC. Besides, bismuth oxides exhibit conductivities about two orders of magnitude higher than those of stabilized zirconia. In this work, yttria doped bismuth oxides were investigated as the ionic conducting phase in a composite cathode for stabilized zirconia. Silver was used to enhance the electronic conductivity of the composite electrodes.

Yttria stabilized bismuth oxide $\left(\mathrm{Y}_{0.25} \mathrm{Bi}_{0.75} \mathrm{O}_{1.5}\right)$ (YSB) was synthesized using a coprecipitation method. Stoichiometric amount of $\mathrm{Bi}\left(\mathrm{NO}_{3}\right)_{3} 5 \mathrm{H}_{2} \mathrm{O}$ (Aldrich 98\%) and $\mathrm{Y}\left(\mathrm{NO}_{3}\right)_{3} 6 \mathrm{H}_{2} \mathrm{O}$ (Aldrich 99.9\%) were dissolved in a dilute nitric acid solution, which was then added drop by drop to an oxalic acid solution to form white precipitates. The precipitates were collected by filtration, dried at $120^{\circ} \mathrm{C}$ overnight, 

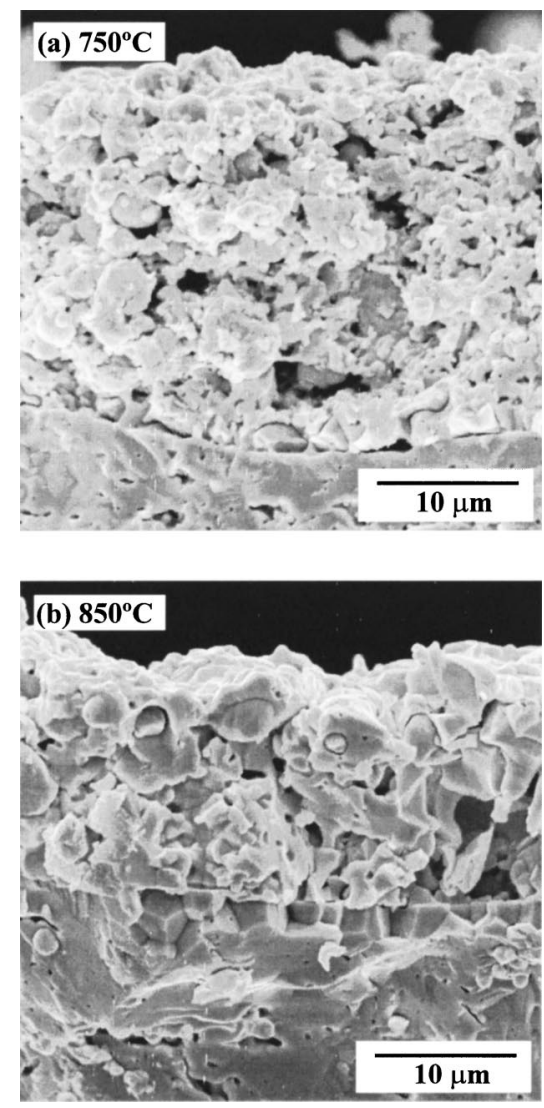

FIG. 1. Cross-sectional views of two YSB-Ag composite cathodes fired at (a) 750 and (b) $850{ }^{\circ} \mathrm{C}$.

and fired at $900{ }^{\circ} \mathrm{C}$ for $5 \mathrm{~h}$ to form crystalline YSB with fluorite structure as confirmed by x-ray diffraction. Silver oxide (Aldrich 99\%), used as the source for electronic conducting component, was mixed with YSB powder at a weight ratio of YSB: $\operatorname{Ag}_{2} \mathrm{O}=40: 60$. The mixed powders were made into a slurry by ball milling for $24 \mathrm{~h}$ with an organic binder and acetone. The slurries were subsequently coated onto the inner channels of a fired YSZ honeycomb with wall thickness of about $300 \mu \mathrm{m} .{ }^{4,5}$ The coated electrode layer was dried at $120^{\circ} \mathrm{C}$ for $2 \mathrm{~h}$ and subsequently fired at 750 or $850^{\circ} \mathrm{C}$ for $2 \mathrm{~h}$ with a heating and cooling rate of 5 and $10^{\circ} \mathrm{C}$ per minute, respectively.

Electrochemical impedance measurements were carried out using a Solartron 1255 HF frequency response analyzer in combination with a Solartron 1286 electrochemical interface. Silver wires were attached to the electrodes with a silver paste, and a thermocouple was positioned close to the sample to monitor the sample temperature, usually increasing from 500 to $750{ }^{\circ} \mathrm{C}$ in $50^{\circ} \mathrm{C}$ interval. Impedance spectra were typically obtained in the frequency range from $1 \mathrm{MHz}$ to $10 \mathrm{mHz}$ with an applied ac voltage amplitude of $10 \mathrm{mV}$. All data was taken $30 \mathrm{~min}$ after the desired temperature was reached. The interfacial impedances as determined from the spectra were corrected for electrode area $\left(0.16 \times 3.0 \mathrm{~cm}^{2}\right)$ and divided by two (symmetric cell) to obtain the area specific polarization resistance $\left(\Omega \mathrm{cm}^{2}\right)$.

Shown in Fig. 1 are the cross-section views of two YSB-Ag composites fired at different temperatures. It can be seen that the composite electrode fired at $750^{\circ} \mathrm{C}$ has high porosity and consists of small grains. In contrast, the com-

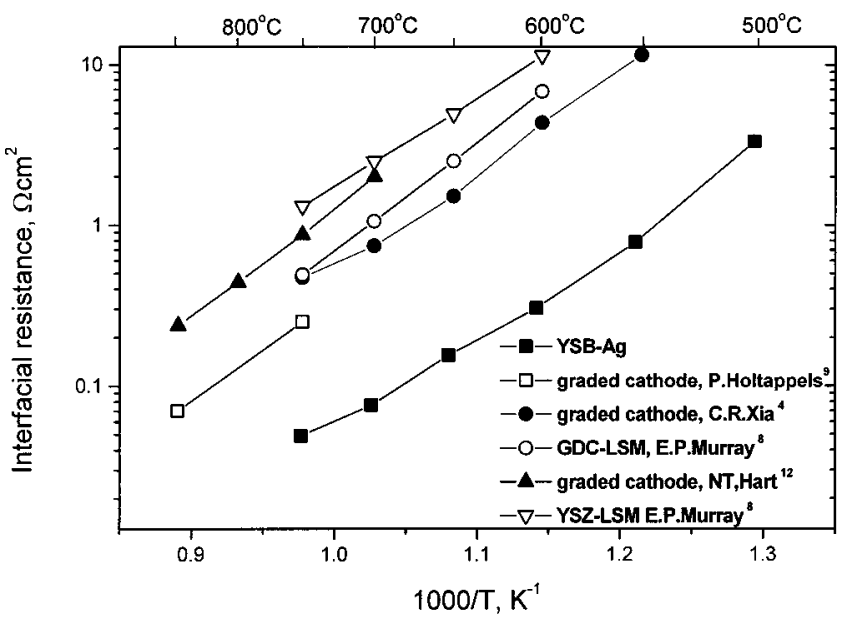

FIG. 2. Interfacial polarization resistances of a YSB-Ag composite cathode, functionally graded cathodes, GDC-LSM, and YSZ-LSM composite cathodes.

posite electrode fired at $850{ }^{\circ} \mathrm{C}$ has isolated pores and consists of large grains. The average thicknesses of the two electrodes are about 25 and $12 \mu \mathrm{m}$, respectively.

The interfacial polarization resistances are determined from the impedance spectra of symmetric cells as described elsewhere. ${ }^{4}$ Shown in Fig. 2 is the temperature dependence of interfacial polarization resistances measured without dc bias for a YSB-Ag cathode fired at $750{ }^{\circ} \mathrm{C}$. Also shown in Fig. 2 are the interfacial polarization resistances of other composite cathodes (YSZ-LSM, GDC-LSM) ${ }^{8}$ and recently developed functionally graded cathodes. ${ }^{4,9,11,12}$ Clearly, the YSB-Ag cathode displays much smaller interfacial polarization resistances than other cathodes. At $600^{\circ} \mathrm{C}$, for example, the interfacial polarization resistance of $\mathrm{YSB}-\mathrm{Ag}$ is only $0.30 \Omega \mathrm{cm}^{2}$, compared to $4.3 \Omega \mathrm{cm}^{2}$ for a graded cathode, ${ }^{4}$ $6.8 \Omega \mathrm{cm}^{2}$ for a GDC-LSM composite, ${ }^{8}$ and $11.4 \Omega \mathrm{cm}^{2}$ for a YSZ-LSM composite, ${ }^{8}$ implying about one order of magnitude improvement. The performance of a mixedconducting electrode is determined by the ionic and electronic conductivities of the electrode, catalytic activities at the triple phase boundary and electrode surfaces, and the rate of gas transport through the porous electrodes. It is well know that LSM, LSCF, Ag, and most other electrode materials have adequate electronic conductivities. Likewise, transport of gases species through the porous cathodes is usually rapid, and thus the effect of concentration polarization is significantly only when the porosity of the electrode is inadequate or the cell is operated at very high current densities. Often, it is found that the overall performance of a mixed-conducting electrode depends critically on the ionic transport properties and on the catalytic properties for oxygen reduction. ${ }^{13}$ The relatively high oxygen ion conductivity of $\mathrm{YSB}^{14}\left(0.070 \mathrm{~S} \mathrm{~cm}^{-1}\right.$ at $\left.600{ }^{\circ} \mathrm{C}\right)$, compared to $\mathrm{GDC}^{15}$ $\left(0.017 \mathrm{~S} \mathrm{~cm}^{-1}\right)$ and $\mathrm{YSZ}^{16}\left(0.0045 \mathrm{~S} \mathrm{~cm}^{-1}\right)$, is clearly an important reason that the $\mathrm{YSB}-\mathrm{Ag}$ composite electrode shows much lower interfacial resistances than the composites consisting of YSZ, GDC, LSM, and LSCF. Moreover, another possible reason is the catalytic effect of YSB on the oxygen disassociation, which is often the limiting step in oxygen reduction at the cathode. ${ }^{6,10}$ For YSZ-LSM and GDC-LSCF it is suggested that the oxygen disassociation 


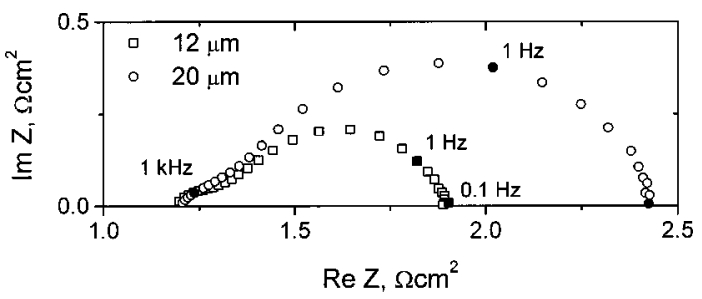

FIG. 3. Impedance spectra measured at $600^{\circ} \mathrm{C}$ for two YSB-Ag composite cathodes of different thickness $(12$ and $25 \mu \mathrm{m})$ sintered at $850^{\circ} \mathrm{C}$ for $2 \mathrm{~h}$.

rate have to be enhanced by at least two orders of magnitude to account for the desired cathodic performance at low temperature. ${ }^{6}$ While there is no data available for direct comparison in catalytic activity for oxygen reduction between YSB and YSZ or GDC, previous work on bismuth oxide based materials demonstrated that the activity of bismuth oxide surface is higher than that of noble metals. This effect was clearly demonstrated using a bismuth lead oxide electrolyte, which was shown to easily support high current densities using a special cell design in which the electronic surface conductivity was provided by means of a thin gold grid cosintered with the electrolyte. ${ }^{17,18}$ It should be noted that silver could also contribute to the observed enhancement in performance since silver is also a very good oxygen reduction catalyst.

Shown in Fig. 3 are two typical impedance spectra measured at $600{ }^{\circ} \mathrm{C}$ for two YSB-Ag composite electrodes fired at $850^{\circ} \mathrm{C}$ for $2 \mathrm{~h}$. The cross-section view of the $12-\mu \mathrm{m}$-thick cathode is shown in Fig. 1(b). The interfacial polarization resistance seems to be proportional to the thickness of the electrodes, indicating that the overall interfacial impedances were determined primarily by the resistance to gas transport through the electrodes. Each spectrum consists of two semicircles from visual inspection. The resistances corresponding to the low frequency semicircle are 0.57 and $1.09 \Omega \mathrm{cm}^{2}$ for the cathodes with thickness of 12 and $20 \mu \mathrm{m}$, respectively.

Shown in Figs. 4(a) and 4(b) are the impedance spectra measured at $600{ }^{\circ} \mathrm{C}$ for two porous YSB-Ag composite electrodes fired at $750{ }^{\circ} \mathrm{C}$ with average thickness of 12 and 25 $\mu \mathrm{m}$, respectively. The two spectra are almost identical, indicating that their electrochemical performances are indepen-

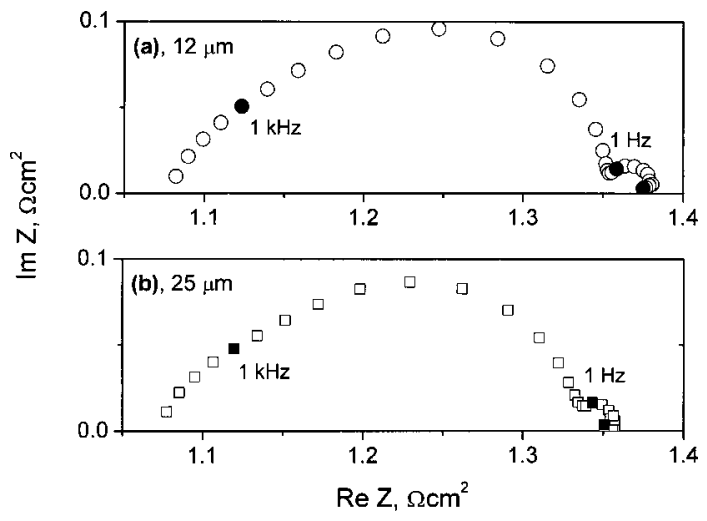

FIG. 4. Impedance spectra measured at $600^{\circ} \mathrm{C}$ for two $\mathrm{YSB}-\mathrm{Ag}$ composite cathodes of different thickness $(12$ and $25 \mu \mathrm{m})$ sintered at $750{ }^{\circ} \mathrm{C}$ for $2 \mathrm{~h}$. dent of their thickness. The electrochemical performances are determined critically by its TPBs, which are related to its structures and microstructures. Since the two electrodes have the same structures except thickness, it can be concluded that the gas transport is efficient through the YSB-Ag composites thinner than $25 \mu \mathrm{m}$; it can also be concluded that the active or useful thickness of the electrode is smaller than 12 $\mu \mathrm{m}$.

While the long-term stability of bismuth oxide-based cathodes in SOFCs is yet to be studied, many previous studies seem to suggest that YSB is stable under the operating conditions studied. For example, it is reported that YSB is chemically stable in partial pressure of oxygen as low as $10^{-13}, 10^{-14}$, and $10^{-20}$ atm under different conditions, as discussed in a review article on bismuth based oxide electrolytes. ${ }^{14}$ Also, the interface between YSZ and YSB seems to be clean and there was no detectible evidence suggesting any reactions between YSZ and YSB; this is consistent with previous studies reported in the literature. ${ }^{19,20}$ However, the microstructural stability of the YSB-Ag composite electrode could be a concern because of the relatively low melting points of both YSB and silver. Thus, YSB-Ag composite electrode is an excellent cathode only for lowtemperature SOFCs.

The authors wish to gratefully acknowledge Kevin Hurysz, J. K. Lee, and Joe Cochran for fabrication of the YSZ honeycomb samples. The authors also wish to gratefully acknowledge the support of this research by Department of Energy (Grant No. DE-FG26-01NT41274) and the DARPA/DSO Palm Power program directed by Dr. Browning and funded through ARMY/ARO Grant No. DAAD1901-1-0649 monitored by Dr. Richard Paur.

${ }^{1}$ E. P. Murray, T. Tsai, and S. A. Barnett, Nature (London) 400, 649 (1999).

${ }^{2}$ Y. Jiang and A. V. Virkar, J. Electrochem. Soc. 148, A706 (2001).

${ }^{3}$ S. Souza, S. J. Visco, and L. C. Jonghe, J. Electrochem. Soc. 144, L35 (1997).

${ }^{4}$ C. R. Xia, W. Rauch, W. Wellborn, and M. L. Liu, Electrochem. SolidState Lett. 5, A217 (2002).

${ }^{5}$ C. R. Xia, W. Rauch, J. Cochran, J. Lee, and M. L. Liu, Proceeding of 1st International Conference on Materials Processing for Properties and Performance (MP3), Aug. 1, 2002, Singapore.

${ }^{6}$ B. C. H. Steele, K. M. Hori, and S. Uchino, Solid State Ionics 135, 445 (2000).

${ }^{7}$ C. Xia and M. Liu, Adv. Mater. 14, 521 (2002).

${ }^{8}$ E. P. Murray and S. A. Barnett, Solid State Ionics 143, 265 (2001).

${ }^{9}$ P. Holtappels and C. Bagger, J. Eur. Ceram. Soc. 22, 41 (2002).

${ }^{10}$ J. C. Boivin and G. Mairesse, Chem. Mater. 10, 2870 (1998).

${ }^{11}$ N. T. Hart, N. P. Brandon, M. J. Day, and J. E. Shemilt, J. Mater. Sci. 36, 1077 (2001).

${ }^{12}$ N. T. Hart, N. P. Brandon, M. J. Day, and N. Lapena-Rey, J. Power Sources 106, 42 (2002).

${ }^{13}$ M. L. Liu, J. Electrochem. Soc. 145, 142 (1998).

${ }^{14}$ N. M. Sammes, G. A. Tompsett, H. Nafe, and F. Aldinger, J. Eur. Ceram. Soc. 19, 1801 (1999).

${ }^{15}$ C. R. Xia and M. L. Liu, Solid State Ionics 152-153, 423 (2002).

${ }^{16}$ S. P. S. Badwal, F. T. Ciacchi, S. Rajendran, and J. Drennan,Solid State Ionics 109, 167 (1998).

${ }^{17}$ M. Dumelie, G. Nowogrocki, and C. J. Boivin, Br. Ceram. Proc. 43, 151 (1988).

${ }^{18}$ M. Dumelie, G. Nowogrocki, and C. J. Boivin, Solid State Ionics 28-30, 524 (1988).

${ }^{19}$ M. J. Miyayama, T. Nishi, and H. Yanagida, J. Mater. Sci. 22, 2624 (1987).

${ }^{20}$ K. Keizer, A. J. Burggraaf, and G. deWith, J. Mater. Sci. 17, 1095 (1982). 